\title{
Relationship between Mean Arterial Pressure, Uric Acid and Calcium with Xanthine Oxidase Activity and Fetal Outcome in Normotensive and Preeclampsia in a Nested Study
}

\author{
Ranjeeta Gadde', Dayanand Chikkanayakanahalli Doddaiah ${ }^{*}$, Sheela Shimoga Rangappa² \\ ${ }^{1}$ Department of Biochemistry, Sri Devaraj Urs Medical College, SDUAHER, Tamaka, Kolar, India \\ ${ }^{2}$ Department of Obstetrics and Gynaecology, Sri Devaraj Urs Medical College, SDUAHER, Tamaka, Kolar, India \\ Email: ranjeetanksr@gmail.com, *cd8905@yahoo.co.in, co.ahs@sduu.ac.in
}

How to cite this paper: Gadde, R., Doddaiah, D.C. and Rangappa, S.S. (2018) Relationship between Mean Arterial Pressure, Uric Acid and Calcium with Xanthine Oxidase Activity and Fetal Outcome in Normotensive and Preeclampsia in a Nested Study. Open Journal of Obstetrics and Gynecology, 8, 1532-1548.

https://doi.org/10.4236/ojog.2018.814154

Received: November 7, 2018

Accepted: December 18, 2018

Published: December 21, 2018

Copyright $(0) 2018$ by authors and Scientific Research Publishing Inc. This work is licensed under the Creative Commons Attribution International License (CC BY 4.0).

http://creativecommons.org/licenses/by/4.0/ Open Access

\begin{abstract}
Preeclampsia is a pregnancy complication; early identification with increased risk is one of the key goals in obstetrics. In a nested case control study, serum uric acid and calcium measured in first and second trimesters of pregnancy were correlated with Xanthine oxidase (XO) activity, mean arterial pressure (MAP) and fetal birth weight. The mean \pm SD of uric acid $(2.01 \pm 0.85,4.8 \pm$ $1.93)$, calcium $(10.88 \pm 1.97,9.72 \pm 2.04)$, MAP $(84.32 \pm 6.71,78.40 \pm 8.53)$ and XO activity $(11.96 \pm 1.91,14.05 \pm 3.09)$ of the study group $(\mathrm{n}=86)$ were observed in the first and second trimesters respectively. First trimester normotensive group $(n=79)$ and preeclampsia cases $(n=7)$, showed a mean $\pm S D$ of uric acid $(1.93 \pm 0.80,2.9 \pm 0.88)$, Calcium (10.92 $\pm 1.9,10.6 \pm 1.72)$, MAP $(84.19 \pm 6.75,85.71 \pm 6.58) \mathrm{XO}$ activity $(11.82 \pm 1.83,13.57 \pm 2.21)$. In the second trimester, normotensive group and preeclampsia cases showed a mean \pm SD uric acid $(4.6 \pm 1.75,7.3 \pm 2.19)$, Calcium $(9.4 \pm 1.85,12.9 \pm 1.04)$, MAP $(76.41 \pm 5.41,100.95 \pm 2.52)$ and XO activity $(13.37 \pm 1.93,21.70 \pm$ 3.50). Statistical analysis revealed a non-significant positive correlation in first trimester between uric acid and MAP $(r=+0.116, p=0.288)$, negative correlations between uric acid and fetal birth weight $(r=-0.118,0.279)$ and between calcium and MAP $(r=-0.288, p=0.007)$. In the second trimester, significant positive correlations were observed between uric acid $(r=+0.246, p=$ $0.022)$, calcium $(r=+0.326, p=0.007)$ with MAP along with a significant negative correlation between uric acid $(\mathrm{r}=-0.641, \mathrm{p}=0.000)$, calcium $(\mathrm{r}=-0.316, \mathrm{p}$ $=0.003)$, Proteinuria $(\mathrm{r}=-0.514, \mathrm{p}=0.000)$ with fetal birth weight. The screening of first and second trimesters $\mathrm{XO}$ activity, uric acid, calcium and MAP during pregnancy is beneficial in identifying women likely to develop
\end{abstract}


preeclampsia with poor fetal outcome.

\section{Keywords}

Uric Acid, Mean Arterial Pressure, Preeclampsia, Nested Case-Control, Fetal Outcome

\section{Introduction}

Preeclampsia is a pregnancy induced hypertensive disorder with an incidence of $2 \%-8 \%$ of pregnant women worldwide [1]. It contributes to maternal/neonatal mortality and morbidity particularly in developing countries where there is poor antenatal care, illiteracy, lack of awareness and poverty [2]. As per American College of Obstetrics and Gynecology Task Force on Hypertension in Pregnancy, the diagnosis of preeclampsia requires blood pressure $\geq 140 / 90 \mathrm{mmHg}$ with renal insufficiency, impaired liver function, hematological and neurological complications [3]. Preeclampsia can cause unfavorable pregnancy outcomes like fetal growth restriction with oligohydramnios, preterm birth, low birth weight, severe birth asphyxia, still birth or intrapartum death [4]. It is a disease of the placenta that results from insufficient trophoblast invasion leading to oxidative stress, inflammation and endothelial dysfunction [5]. As there is no curative treatment, except removal of the placenta, early diagnosis of this obstetric disorder by using simple tests could aid in management for improvement of pregnancy outcomes.

In first trimester of pregnancy, serum uric acid levels found to fall less than 3 $\mathrm{mg} / \mathrm{dL}$ due to estrogen effect, expanded blood volume and increased glomerular filtration rate. The levels slowly increase as gestation proceeds up to $5 \mathrm{mg} / \mathrm{dL}$ by term [6]. However, women who are at risk for developing preeclampsia have elevated levels of uric acid as early as 10 weeks of gestation prior to the presence of proteinuria or hypertension [7]. Studies suggest that hyperuricemia is not only a prognostic indicator of maternal and fetal complications in preeclampsia but also correlates with the disease progression and contributes to its pathogenesis by virtue of its ability in promoting inflammation, oxidative stress and endothelial dysfunction in both placenta and maternal vasculature [8] [9] [10].

Calcium not only helps in mineralization of fetal bone and teeth but also plays a crucial role as a second messenger in many signaling pathways in the placenta [11]. The intracellular calcium is also known to play a key role in blastocyst implantation, placental development and function [12]. Hence, alterations in maternal calcium homeostasis could be associated with impaired placental function that can contribute to preeclampsia and adverse fetal outcomes [13] [14].

Mean arterial pressure (MAP), a biophysical marker is known to be a better predictor for screening preeclampsia [15] [16]. It represents average pressure in a patient's arteries during one cardiac cycle and is considered as a better indica- 
tor of perfusion to vital organs than systolic blood pressure. MAP derived by calculation presented by Park H.J. et al. [17]. The formula describes doubling the diastolic blood pressure (DBP), addition to the systolic blood pressure (SBP) divided by 3 i.e., $(\mathrm{MAP}=\mathrm{SBP}+2(\mathrm{DBP}) / 3)$. Few studies reported increased MAP in prediction of preeclampsia during gestation period intervals.

Xanthine oxidase (XO) or xanthine oxido-reductase catalyzes the oxidation of hypoxanthine and xanthineto uric acid. The information available on the importance of serum XO activity, serum calcium and uric acid in all trimesters of pregnancy and preeclampsia followed by pregnancy outcome is limited. Therefore, in this study context, an attempt was made to consider these parameters as markers to know pregnancy complications and also to evaluate the possible association between serum uric acid, total calcium with XO activity, MAP and fetal outcome in normotensive pregnants and preeclamptic cases in a nested group.

\section{Materials and Methods}

\subsection{Materials}

The study was conducted in joint collaboration of Department of Biochemistry with Department of Obstetrics and Gynaecology in R. L. Jalappa Hospital and Research Centre, Kolar, Karnataka, between August 2017-May 2018. Clinically confirmed pregnant women at first trimester were enrolled after obtaining informed consent and followed till delivery. Ethical clearance for the study was obtained from Central ethics Committee bearing No. SDUAHER/KLR/R\&D/47/ 2017-18.

\subsection{Sample Collection}

The study design was a nested case control. Three milliliters of blood was collected from anti-cubital vein under aseptic conditions using vacutainer from pregnants under non-fasting conditions in first (8 - 11 weeks) and second trimester (19 - 24 weeks) during their visit to the Department of Obstetrics and Gynaecology for regular antenatal check-up. Blood was allowed to retract, centrifuged at $3000 \mathrm{rpm}$ at room temperature for 20 minutes to get clear serum and stored at $-20^{\circ} \mathrm{C}$ until analysis.

\subsection{Inclusion Criteria}

This study has 86 pregnant women of primigravida with singleton pregnancy visited for antenatal check-up in first trimester and second trimester of gestation in the age group of 20 - 35 years were included and followed until delivery to record fetal outcome.

\subsection{Exclusion Criteria}

Pregnant women with history of hypertension, liver disease and renal failure, hyperparathyroidism, cardiovascular or any vascular diseases were excluded from the study. 


\section{Methods}

SBP and DBP were measured in pregnant women using a sphygmomanometer at first and second trimester of pregnancy. MAP was calculated by using the formula described by Katz 2004 which was adapted in research work of Park HJ et al. in 2015 [17] [18].

The formula describes doubling the diastolic blood pressure (DBP), addition to the systolic blood pressure (SBP) divided by 3 i.e., $(\mathrm{MAP}=\mathrm{SBP}+2(\mathrm{DBP}) / 3)$.

Serum total calcium was measured by Arsenazo III dye method, where calcium reacts with dye to produce purple colored complex that was measured in dry chemistry analyzer Vitros FS5.1 (Johnson and Johnson, USA).

Serum uric acid was measured by Uricase enzymatic method. Uric acid in the sample was catalyzed by uricase to produce allantoin, carbon dioxide and hydrogen peroxide. By the action of Peroxidase and in the presence of phenolderivative,3,5-Dichloro-2-hydroxy-benzenesulfonic acid and 4-Aminoantipyrine, Hydrogen peroxide gives a red colored quinone complex that was measured in dry chemistry analyzer Vitros FS5.1 (Johnson and Johnson, USA).

The assay of serum Xanthine oxidase activity was carried out by colorimetric method as per the procedure supplied by Biovision, USA. XO oxidizes xanthine to hydrogen peroxide which reacts stoichiometrically with OxiRed ${ }^{\mathrm{TM}}$ Probe to generate pink color. The absorbance of the pink colour was measured at $570 \mathrm{~nm}$.

\section{Statistical Analysis}

The obtained data was subjected for statistical analysis by using licensed version of SPSS 20. All variables were expressed as mean, \pm SD. Data was checked for normality. Since the data was not normally distributed, the significance of difference in the mean of the measured parameters in first and second trimester of pregnancy was calculated by a non-parametric Wilcoxon rank sum test. Pearson's Correlation ( $r$ ) was applied to find the association between serum uric acid and total calcium with XO activity, MAP and fetal birth weight. Mann-Whitney unpaired test was used for comparison of non-normally distributed data between the preeclampsia and control group. p value less than 0.05 ( $\mathrm{p}<0.05$ ) was considered to indicate statistical significance.

\section{Results}

Eighty Six women were enrolled in the study and followed in their first and second trimester of pregnancy till delivery. Table 1 displays the mean \pm SD of the demographic variables of the pregnant group $(n=86)$ in first and second trimester. The mean \pm SD of the hematological and biochemical parameters in first and second trimester are shown in Table 2 . The mean \pm SD of the study parameters in the first and second trimester are shown in Table 3. The first and second trimester mean \pm SD values of the study subjects for SBP $(108.13 \pm 8.74$, $101.04 \pm 10.40)$, DBP $(72.20 \pm 7.57,67.09 \pm 8.79)$, MAP $(84.32 \pm 6.71,78.40 \pm$ $8.53)$, serum uric acid $(2.01 \pm 0.85,4.8 \pm 1.93)$, serum total calcium $(10.88 \pm$ 
$1.97,9.72 \pm 2.04)$ and serum XO activity $(11.96 \pm 1.91,14.05 \pm 3.09)$ respectively. Data checked for normality. Since the data was not normally distributed, Wicoxon rank sum test was used to determine the mean difference between the two sets of observations. $\mathrm{p}$ value less than 0.05 was considered statistically significant.

Serum uric acid and calcium were correlated with MAP, XO activity and fetal birth weight in first and second trimesters of pregnancy using Pearson's correlation, $\mathrm{p}$ value less than 0.05 considered statistically significant. The level of significance and correlation of the study parameters were tabulated Table 4. Graphical representation of positive and negative correlations is shown in Figure 1 \& Figure 2.

In first trimester, a positive non-significant correlation was observed between uric acid and MAP $(r=+0.116, p=0.288)$. A positive non-significant correlation was observed between uricacid and serum XO activity $(+0.170, \mathrm{p}=0.117)$. A negative correlation was observed between uric acid and fetal birth weight $(\mathrm{r}=$ $-0.118, \mathrm{p}=0.279)$, calcium and XO activity $(\mathrm{r}=-0.105, \mathrm{p}=0.328)$ with no

Table 1. Demographic variables of the study group in first trimester and second trimester of pregnancy.

\begin{tabular}{ccc}
\hline Maternal Variables & $\begin{array}{c}\text { First trimester }(\mathrm{n}=\mathbf{8 6}) \\
\text { Mean } \pm \text { SD }\end{array}$ & $\begin{array}{c}\text { Second trimester }(\mathrm{n}=\mathbf{8 6}) \\
\text { Mean } \pm \text { SD }\end{array}$ \\
\hline Age (years) & $24.86 \pm 1.33$ & $24.86 \pm 1.33$ \\
Body weight (kg) & $50.30 \pm 8.99$ & $65.84 \pm 7.74$ \\
Systolic blood pressure (mm Hg) & $108.13 \pm 8.74$ & $101.04 \pm 10.40$ \\
Diastolic blood pressure (mm Hg) & $72.20 \pm 7.57$ & $67.09 \pm 8.79$ \\
Mean Arterial Pressure & $84.32 \pm 6.71$ & $78.40 \pm 8.53$
\end{tabular}

SD: Standard Deviation.

Table 2. Hematological and biochemical parameters of the study group in first and second trimester of pregnancy.

\begin{tabular}{cccc}
\hline Parameters & $\begin{array}{c}\text { First trimester } \\
\text { Mean } \pm \text { SD }\end{array}$ & $\begin{array}{c}\text { Second trimester } \\
\text { Mean } \pm \text { SD }\end{array}$ & p value \\
Haemoglobin $($ gm \%) & $11.12 \pm 1.99$ & $9.21 \pm 1.22$ & $0.000^{*}$ \\
Platelets $\left(10^{3} / \mu \mathrm{L}\right)$ & $289.62 \pm 79.42$ & $203.2 \pm 35.6$ & $0.000^{*}$ \\
Total Count $\left(\mathrm{mm}^{3}\right)$ & $9.44 \pm 2.03$ & $8.21 \pm 1.21$ & $0.000^{*}$ \\
MCV (Fl/red cell) & $81.55 \pm 9.56$ & $79.33 \pm 1.51$ & 0.234 \\
MCH (pg/cell) & $26.71 \pm 3.43$ & $25.43 \pm 2.15$ & 0.328 \\
Bleeding time (minutes) & $2.00 \pm 0.00$ & $1.96 \pm 0.16$ & 0.245 \\
Clotting time (minutes) & $4.58 \pm 1.91$ & $4.22 \pm 1.32$ & 0.123 \\
Random blood sugar $(\mathrm{mg} / \mathrm{dL})$ & $98.54 \pm 17.73$ & $101.34 \pm 12.22$ & $0.000^{*}$ \\
Serum creatinine (mg/dL) & $0.66 \pm 0.12$ & $0.59 \pm 0.10$ & $0.000^{*}$ \\
Blood Urea (mg/dL) & $23.06 \pm 4.10$ & $21.34 \pm 2.21$ & $0.000^{*}$ \\
\hline
\end{tabular}

${ }^{*} \mathrm{p}<0.05$ - statistically significant by Wilcoxon rank sum test; SD: Standard Deviation. 
Table 3. Showing mean, \pm SD of the study parameters in first and second trimester of pregnancy.

\begin{tabular}{cccc}
\hline Variable & $\begin{array}{c}\text { First trimester } \\
\text { Mean } \pm \text { SD }\end{array}$ & $\begin{array}{c}\text { Second trimester } \\
\text { Mean } \pm \text { SD }\end{array}$ & p value \\
\hline SBP $(\mathrm{mmHg})$ & $108.13 \pm 8.74$ & $101.04 \pm 10.40$ & $0.000^{*}$ \\
DBP $(\mathrm{mmHg})$ & $72.20 \pm 7.57$ & $67.09 \pm 8.79$ & $0.000^{*}$ \\
MAP & $84.32 \pm 6.71$ & $78.40 \pm 8.53$ & $0.000^{*}$ \\
Serum uric acid $(\mathrm{mg} / \mathrm{dL})$ & $2.01 \pm 0.85$ & $4.8 \pm 1.93$ & $0.000^{\star}$ \\
Serum total calcium $(\mathrm{mg} / \mathrm{dL})$ & $10.88 \pm 1.97$ & $9.72 \pm 2.04$ & $0.000^{*}$ \\
Serum XO activity $(\mathrm{mU} / \mathrm{mL})$ & $11.96 \pm 1.91$ & $14.05 \pm 3.09$ & $0.000^{*}$ \\
\hline
\end{tabular}

${ }^{*} \mathrm{p}<0.05$-statistically significant by Wilcoxon rank sum test; SBP: systolic blood pressure DBP: diastolic blood pressure MAP: mean arterial pressure FBW: fetal birth; weight XO: xanthine oxidase SD: Standard Deviation.

Table 4. Showing positive and negative correlations between serum uric acid and total calcium with mean arterial pressure and fetal birth weight in first and second trimesters of pregnancy.

\begin{tabular}{cccccc}
\hline First trimester & \multicolumn{5}{c}{ Second trimester } \\
\hline Positive correlation & $\mathbf{p}$ & $\mathbf{r}$ & Positive correlation & $\mathbf{p}$ & $\mathbf{r}$ \\
\hline Uric acid and MAP & 0.288 & +0.116 & Uric acid and MAP & $0.022^{*}$ & +0.246 \\
Uric acid and XO & 0.117 & +0.170 & Calcium and MAP & $0.007^{*}$ & +0.326 \\
& & & Calcium and XO & $0.003^{*}$ & +0.322 \\
& & & Uric acid and XO & $0.040^{*}$ & +0.222 \\
Negative correlation & & & & & \\
Uric acid and FBW & 0.279 & -0.118 & Uric acid and FBW & $0.000^{*}$ & -0.641 \\
Calcium and MAP & $0.007^{*}$ & -0.288 & Calcium and FBW & $0.003^{*}$ & -0.316 \\
Calcium and XO & 0.328 & -0.105 & Proteinuria and FBW & $0.000^{*}$ & -0.514 \\
\hline
\end{tabular}

${ }^{*} \mathrm{p}<0.05$ - statistically significant by Pearson's correlation; MAP: mean arterial pressure, FBW: fetal birth weight, XO: xanthine oxidase.

significance. A significant negative correlation was observed between calcium and $\mathrm{MAP}(\mathrm{r}=-0.288, \mathrm{p}=0.007)$.

In second trimester, a significant positive correlation was observed between uric acid and MAP $(r=+0.246, p=0.022)$. A significant positive correlation was also observed between calcium and MAP $(r=+0.326, p=0.007)$. A significant negative correlation was observed between uric acid and fetal birth weight $(\mathrm{r}=$ $-0.641, p=0.000)$. A negative correlation was also observed between calcium and fetal birth weight $(\mathrm{r}=-0.316, \mathrm{p}=0.003)$ and between proteinuria and fetal birth weight $(r=-0.514, p=0.000)$ with significance. A significant positive correlation was observed between serum uric acid and xanthine oxidase activity in second trimester $(\mathrm{r}=+0.222, \mathrm{p}=0.040)$

The mean \pm SD of the demographic and biochemical parameters in preeclampsia and normotensive subjects are tabulated in Table 5. Mann-Whitney 
unpaired test was used for comparison of non-normally distributed data. $\mathrm{P}<$ 0.05 was considered statistically significant. Compared to the normotensive group, women who translated into preeclampsia showed statistical significance in the maternal age $(25.04 \pm 1.22$ vs. $22.85 \pm 0.69, \mathrm{p}=0.000)$. In the first trimester, there was no significant difference in the blood pressure (SBP, DBP and MAP) and calcium levels in both controls and preeclampsia group. First trimester uric acid levels $(2.9 \pm 0.88$ vs. $1.93 \pm 0.80, \mathrm{p}=0.005)$ and serum XO activity $(13.57 \pm 2.21$ vs. $11.82 \pm 1.83 \mathrm{p}=0.017)$ were significantly higher in preeclampsia when compared to the controls respectively. In the second trimester, the preeclampsia and control group showed significant difference in SBP (125.71 \pm 5.34 vs.

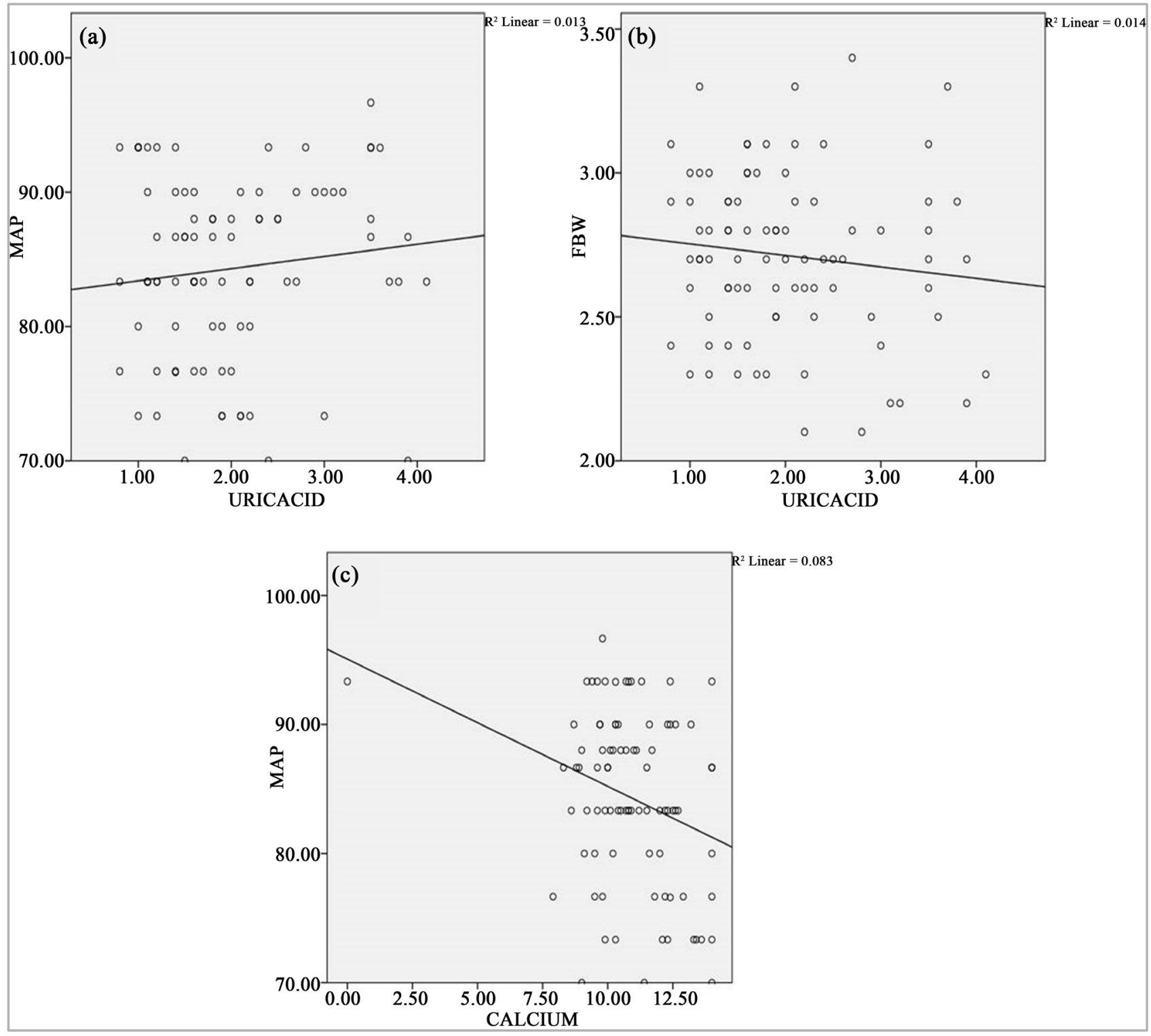

Figure 1. Showing the graphical representation of correlations between the study parameters in first trimester of pregnancy. (a) Positive correlation between uric acid and mean arterial pressure $(r=+0.116, p=0.288)$; (b) Negative correlation between uric acid and fetal birth weight $(\mathrm{r}=-0.118, \mathrm{p}=0.279)$; (c) Negative correlation between calcium and mean arterial pressure $(\mathrm{r}=$ $-0.288,0.007)$. 


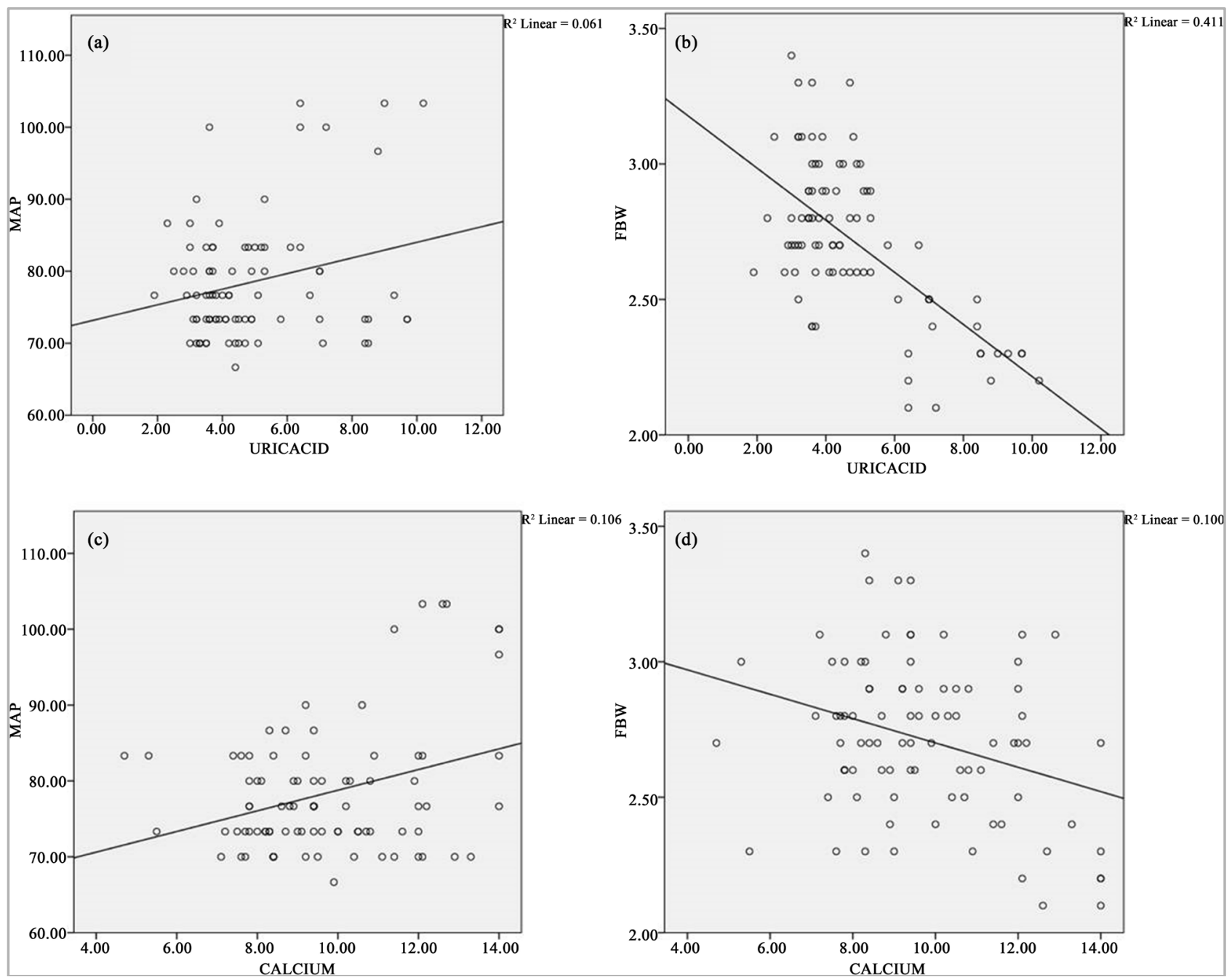

Figure 2. Showing the graphical representation of correlations between the study parameters in second trimester of pregnancy. (a) Significant positive correlation between uric acid and MAP $(r=0.246, p=0.022)$; (b) Significant negative correlation between uric acid and fetal birth weight $(r=-0.641, \mathrm{p}=0.000)$; (c) Significant positive correlation between calcium and MAP $(r=0.326, \mathrm{p}=$ 0.002); (d) Significant negative correlation between calcium and fetal birth weight $(r=0.361, p=0.003)$.

$98.86 \pm 7.52, \mathrm{p}=0.000), \mathrm{DBP}(88.57 \pm 3.77$ vs. $65.18 \pm 6.17, \mathrm{p}=0.000), \mathrm{MAP}$ $(100.95 \pm 2.52$ vs. $76.41 \pm 5.41, \mathrm{p}=0.000)$, serum uric acid $(7.3 \pm 2.19$ vs. $4.6 \pm$ $1.75, \mathrm{p}=0.003)$, XO activity ( $21.70 \pm 3.50$ vs. $13.37 \pm 1.93, \mathrm{p}=0.000)$, Proteinuria ( 2 vs. $0, \mathrm{p}=0.000)$, delivery age in weeks $(36.14 \pm 1.06$ vs. $38.96 \pm 0.912, \mathrm{p}$ $=0.000)$, fetal birth weight $(2.21 \pm 10.10$ vs. $2.75 \pm 0.25, \mathrm{p}=0.000)$ respectively.

\section{Discussion}

Eighty-six normotensive pregnant women were followed from first trimester during their prenatal care visit until delivery. The samples were analysed in first and second trimesters for the quantification of serum uric acid, total calcium and also to identify their relationship with MAP, XO activity and fetal outcome. The results indicated seven cases developed preeclampsia which amounts to $8.1 \%$ from the study group $(\mathrm{n}=86)$. The remaining seventy-nine pregnant 
Table 5. Demographic characteristics and biochemical parameters normotensive and preeclampsia subjects in the study.

\begin{tabular}{|c|c|c|c|}
\hline Variables & Normotensive $(n=79)$ & Preeclampsia $(n=7)$ & p-value \\
\hline \multicolumn{4}{|l|}{ Demographic } \\
\hline Maternal age (years) & $25.04 \pm 1.22$ & $22.85 \pm 0.69$ & $0.000^{*}$ \\
\hline Primiparous & $100 \%$ & $100 \%$ & 1.000 \\
\hline \multicolumn{4}{|l|}{ First trimester } \\
\hline Maternal SBP (mmHg) & $108.10 \pm 8.92$ & $108.57 \pm 6.90$ & 0.960 \\
\hline Maternal DBP (mmHg) & $72.20 \pm 7.57$ & $74.28 \pm 7.86$ & 0.405 \\
\hline Maternal MAP (mmHg) & $84.19 \pm 6.75$ & $85.71 \pm 6.58$ & 0.539 \\
\hline \multicolumn{4}{|l|}{ Serological parameters } \\
\hline Maternal serum uric acid $(\mathrm{mg} / \mathrm{dL})$ & $1.93 \pm 0.80$ & $2.9 \pm 0.88$ & $0.005^{\star}$ \\
\hline Maternal serum total calcium $(\mathrm{mg} / \mathrm{dL})$ & $10.92 \pm 1.9$ & $10.6 \pm 1.72$ & 0.497 \\
\hline Maternal serum XO activity $(\mathrm{mU} / \mathrm{mL})$ & $11.82 \pm 1.83$ & $13.57 \pm 2.21$ & $0.017^{\star}$ \\
\hline \multicolumn{4}{|l|}{ Second trimester } \\
\hline Maternal SBP (mmHg) & $98.86 \pm 7.52$ & $125.71 \pm 5.34$ & $0.000^{*}$ \\
\hline Maternal DBP (mmHg) & $65.18 \pm 6.17$ & $88.57 \pm 3.77$ & $0.000^{*}$ \\
\hline Maternal MAP (mmHg) & $76.41 \pm 5.41$ & $100.95 \pm 2.52$ & $0.000^{*}$ \\
\hline \multicolumn{4}{|l|}{ Serological parameters } \\
\hline Maternal serum uric acid (mg/dL) & $4.6 \pm 1.75$ & $7.3 \pm 2.19$ & $0.003^{*}$ \\
\hline Maternal serum total calcium $(\mathrm{mg} / \mathrm{dL})$ & $9.4 \pm 1.85$ & $12.9 \pm 1.04$ & $0.000^{*}$ \\
\hline Maternal serum XO activity $(\mathrm{mU} / \mathrm{mL})$ & $13.37 \pm 1.93$ & $21.70 \pm 3.50$ & $0.000^{*}$ \\
\hline Proteinuria (g/day) & 0 & 2 & $0.000^{*}$ \\
\hline \multicolumn{4}{|l|}{ Fetal outcome } \\
\hline Delivery age (weeks) & $38.96 \pm 0.912$ & $36.14 \pm 1.06$ & $0.000^{*}$ \\
\hline Fetal birth weight (kgs) & $2.75 \pm 0.25$ & $2.21 \pm 0.10$ & $0.000^{*}$ \\
\hline
\end{tabular}

${ }^{*} \mathrm{p}<0.05$ statistically significant by Mann-Whitney U test. SBP: systolic blood pressure DBP: diastolic blood pressure MAP: mean arterial pressure XO: xanthine oxidase.

women without pregnancy complications were studied as control group.

A significant decrease was observed in the mean of SBP, DBP and MAP from first trimester to second trimester of pregnancy. Study results are in line with the reports of Rebelo F. et al. They reported a decrease in SBP and DBP from first to the second trimester [19]. The possible explanation for the drop in blood pressure in the second trimester of pregnancy is due to cardiovascular adaptations including increased cardiac output, decreased vascular resistance and other metabolic changes [20]. Similar observations were also reported by studies conducted by HH Klein et al. and Sanghavi M. et al. [21] [22]. In the second trimester, our study results showed increased blood pressure in women who developed preeclampsia. Many studies confirmed the presence of hypertension in second trimester in women who develop preeclampsia. Khalil A. et al. investigated the 
longitudinal changes in the uterine artery mean pulsatility index and MAP in women who developed preeclampsia and gestational hypertension and reported MAP increased from 12 weeks onwards in women who develop preeclampsia [23]. Tayyar A. et al. also reported MAP increases with gestational age in pregnancies that developed preeclampsia and also suggested assessment in the second and third trimesters aims to identify women at risk of developing preeclampsia [16].

Uric acid is heterocyclic and an end product of purine metabolism; possess biological function as an antioxidant at lower concentrations. During early pregnancy uric acid concentration falls and starts rising towards third trimester. This initial drop is due touricosuric effect of estrogen, expanded blood volume and increased glomerular filtration rate [10] and the rise in late pregnancy may be secondary to increased fetal production, decreased binding to albumin and increased tubular reabsorption [24]. In the present study, a significant increase of uric acid levels from first trimester $(2.01 \pm 0.85)$ to second trimester of pregnancy $(4.8 \pm 1.93)$ was noticed. Our study observations are similar with that of the research work carried out by Powers R.W. et al. and Laughon S.K. et al. [25] [8]. Out of 86 normotensive pregnant women, 7 developed preeclampsia. Serum uric acid levels were measured in control and preeclampsia group in both first and second trimester. The study results showed preeclampsia is associated with increased XO activity and hyperuricemia in first and second trimesters of pregnancy. Increased generation of uric acid is due to increased xanthine oxidase activity in ischaemic placenta, which contributes to the development of hypertension and renal damage in preeclampsia via endothelial dysfunction or renin activation [6].

Studies have reported elevated uric acid levels in pregnancies complicated by preeclampsia and thus of good diagnostic and prognostic value for fetus [9] [26] [27] [28]. Based on these observations, uric acid can be considered as a reliable and cost effective screening test for the early detection of preeclampsia. However there are other studies which have reported the measurement of uric acid levels is not a good predictor of preeclampsia or its complications [29] [30].

In the present study, uric acid positively correlated with MAP in the first trimester $(r=+0.116, p=0.288)$ and second trimester $(r=+0.246, p=0.022)$ of pregnancy. Study results are in agreement with the research work carried out by Zhou G et al. in 2018 where they reported Hyperuricemia and its association with elevated blood pressure during pregnancy [31]. Similarly, Laughon SK et al. in 2011 reported a linear association between elevated uric acid with later development of preeclampsia. He also reported uric acid not only predicts the development of preeclampsia but also contributes to the pathogenesis of the disorder [8]. However, de Jong CL et al. in 1999 also reported the same kind of observations [32].

In our follow-up study, a negative correlation was observed between first trimester $(\mathrm{r}=-0.118, \mathrm{p}=0.279)$ and second trimester $(\mathrm{r}=-0.641, \mathrm{p}=0.000)$ uric 
acid and fetal birth weight. These results are similar with the studies conducted by Aparna Nair et al., Akahori Y. et al. and Yalamati P. et al. where they reported an association between uric acid and severity of preeclampsia with adverse fetal outcome [33] [34] [35]. These observations were experimentally evidenced by a set of in-vitro experiments that demonstrated elevated uric acid decreases endothelial cell proliferation and migration thus placental development [10], impaired placental amino acid uptake, [36] trophoblast invasion and endothelial proliferation [37], thus blocking fetal angiogenesis resulting in small for gestational age (SGA) infants [38]. However, a study by Williams KP et al. 2002 indicated contradictory results that uric acid is not a good prognostic indicator of the severity of the maternal or fetal complications [39].

In this study, measured total calcium was significantly reduced in the second trimester $(9.72 \pm 2.04)$ in comparison to first trimester $(10.88 \pm 1.97)$. The results of the study are similar to the results obtained by Hanna B. et al. who reported reduced total calcium levels in second and third trimester compared to first trimester [40]. The probable reasons for reduced calcium levels in second trimester is due to increased nutritional demands of the growing fetus, expanded intravascular space, reduced albumin concentration, serum PTH is lower by $50 \%$ in pregnancy and increased excretion of calcium as a result of increased GFR [41].

Negative correlation was also observed between serum calcium and MAP in first trimester of pregnancy $(r=-0.288, p=0.007)$. There are research evidences that documented an inverse relationship between intake of calcium in pregnancy and incidence of preeclampsia [42] [43]. In 2011, WHO recommended calcium supplementation with $1.5-2.0 \mathrm{~g}$ per day in calcium deficient pregnant women for the prevention of pregnancy hypertensive disorders [44]. However, few contradictory studies also reported the non-beneficial aspect of calcium in prevention of preeclampsia [45] [46] [47].

Unlike the first trimester, in second trimester, a strong positive correlation was observed between calcium and MAP with significance $(r=+0.326, p=$ $0.007)$. The underlying explanation for the positive correlation might be functional role of calcium, where calcium not only brings about smooth muscle contraction but excess calcium can also cause an increase in peripheral vascular resistance leading to essential hypertension [48]. This biological property of hypercalcemia can be antagonized by using dihydropyridine/nifedipine that blocks influx of extracellular calcium on transmembrane of vascular smooth muscle cells which results in dilatation and reduces the hypertension in preeclampsia and preterm labor [49] [50].

There is limited information available on serum total calcium in relation with fetal birth weight. In the current study indicated significant negative correlation between serum total calcium levels and fetal birth weight $(\mathrm{r}=-0.361, \mathrm{p}=0.003)$. However, the effect of maternal calcium intake and its influence on infant growth remains unclear. The results of the study by Abalos E. et al. and Abdel-Aleem H. et al. also in agreement with current study where they reported 
calcium supplementation has no effect on fetal birth weight [51] [52]. Thoughfew studies have shown calcium intake during pregnancy has a positive effect on the fetal birth weight [53] [54]. The study results also showed significant negative correlation between Proteinuria and fetal birth weight $(\mathrm{r}=-0.514, \mathrm{p}<$ 0.001). The results of this study are in agreement with Tayal et al. who reported severe proteinuria could also be an indicator of adverse fetal outcome [55].

$\mathrm{XO}$ is a metalloenzyme contains iron and molybdenum as an integral component catalyzes the oxidation of xanthine/hypoxanthine into uric acid. Pre-eclampsia occurs only in the presence of placenta which depends on the decreased placental perfusion due to impaired remodeling of spiral arteries. Inadequacy of placental perfusion might result in hypoxic interface between maternal-fetus results in destruction of fetal tissue that can release XO, and substrates like xanthine/hypoxanthine, cytokines etc.

Measurement of XO level in all trimesters of pregnancy is required to understand if gradual increase of $\mathrm{XO}$ activity can act as a marker to denote the number of chances translated into pre-eclampsia. Therefore, in the present study understanding of pre-eclampsia at early stage is a good indication to decide suitable treatment strategies to prevent its onset and pathological changes.

Our study results prominently presents the XO activity of the normotensive group in first $(13.57 \mathrm{mU} / \mathrm{mL})$, second $(21.70 \mathrm{mU} / \mathrm{mL})$ trimesters and in preeclampsia in third trimester $(53.60 \mathrm{mU} / \mathrm{mL})$ of pregnancy as shown in Figure 3. Therefore, $\mathrm{XO}$ can be considered as cost effective parameter to know at early the later onset of preeclampsia along with uric acid and MAP. Uric acid was also positively correlated with XO activity $(\mathrm{r}=+0.170, \mathrm{p}=0.117)$ in first trimester and second trimester $(r=+0.222, p=0.040)$ of pregnancy.

Our study results also focussed on in finding relationship between elevated calcium levels and Proteinuria in preeclampsia when compared to control group

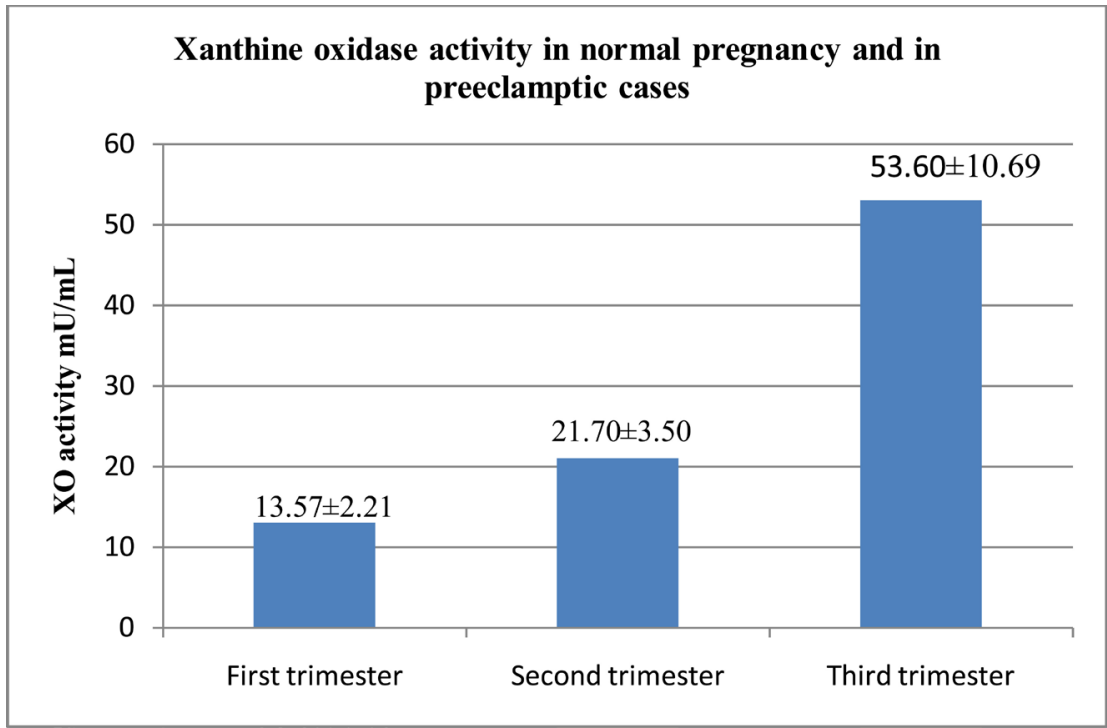

Figure 3. Showing XO activity in I, II trimesters of normal pregnancy and cases developed preeclampsia. 
in second trimester. On successful follow up of the preeclampsia cases showed early gestational age of delivery and low fetal birth weight compared to control group. Supportive evidences to this observation reported by Aabidha P.M. et al. and Seyom E. et al. who showed that neonatal complications like prematurity, growth restriction and low birth weight are generally seen associated with preeclampsia [56] [57].

\section{Limitations}

The limitation of the study is small sample size and non inclusion of other indicators denoting fetal outcome.

\section{Conclusion}

The nested case-control study on normotensive pregnant women evinced measurement of simple cost effective routine parameters like uric acid, calcium and mean arterial pressure serve as good indicators in early understanding of later onset of preeclampsia. First trimester screening is crucial over the second trimester to know the early onset of the disorder associated with the underlying placentation process. Besides, evaluation of xanthine oxidase activity in all trimesters of pregnancy is more informative and becomes newer aspect relating to placental ischemia. The preeclampsia group showed poor fetal outcome i.e., pre-term delivery and low fetal birth weight. Hence, measured biochemical and physical parameters facilitate their effectiveness in early assessment of preeclampsia.

\section{Acknowledgements}

We would like to thank the Authorities of Sri Devaraj Urs Academy of Higher Education and Research and Proteomics research laboratory for supporting this doctoral study.

\section{Conflicts of Interest}

The authors declare that there is no conflict of interest that would prejudice the impartiality of this scientific work.

\section{References}

[1] Steegers, E.A., von Dadelszen, P., Duvekot, J.J. and Pijnenborg, R. (2010) Pre-Eclampsia. Lancet, 376, 631-644.

[2] Hod, T., Cerdeira, A.S. and Karumanchi, S.A. (2015) Molecular Mechanisms of Preeclampsia. Cold Spring Harbor Perspectives in Medicine, 5, pii:a023473.

[3] Townssend, R., O’Brien, P. and Khalil, A. (2016) Current Best Practice in the Management of Hypertensive disorders in pregnancy. Integrated Blood Pressure Control, 9, 79-94.

[4] Odegard, R.A., Vatten, L.J., Nilsen, S.T., Salvesen, K.A. and Austgulen, R. (2000) Preeclampsia and Fetal Growth. Obstetrics \& Gynecology, 96, 950-955.

[5] Tannetta, D. and Sargent, I. (2013) Placental Disease and the Maternal Syndrome of 
Preeclampsia Missing Links? Current Hypertension Reports, 15, 590-599.

[6] Kang, D.H., Finch, J., Nakagawa, T., Karumanchi, S.A., Kanellis, J., Granger, J., et al. (2004) Uric Acid, Endothelial Dysfunction and Pre-Eclampsia: Searching for a Pathogenetic Link. Journal of Hypertension, 22, 229-235.

[7] Roberts, J.M., Bodnar, L.M., Lain, K.Y., Hubel, C.A., Markovic, N., Ness, R.B., et al. (2005) Uric Acid Is as Important as Proteinuria in Identifying Fetal Risk in Women with Gestational Hypertension. Hypertension, 46, 1263-1269.

[8] Laughon, S.K., Catov, J., Powers, R.W., Roberts, J.M. and Gandley, R.E. (2011) First Trimester Uric Acid and Adverse Pregnancy Outcomes. American Journal of Hypertension, 24, 489-495. https://doi.org/10.1038/ajh.2010.262

[9] Asgharnia, M., Mirblouk, F., Kazemi, S., Pourmarzi, D., MahdipourKeivani, M. and DalilHeirati, S.F. (2017) Maternal Serum Uric Acid Level and Maternal and Neonatal Complications in Preeclamptic Women: A Cross-Sectional Study. International Journal of Reproductive Biomedicine, 15, 583-588.

[10] Bainbridge, S.A. and Roberts, J.M. (2008) Uric Acid as a Pathogenic Factor in Preeclampsia. Placenta, 29, S67-S72.

[11] Idogun, E.S., Imarengiaye, C.O. and Momoh, S.M. (2007) Extracellular Calcium and Magnesium in Preeclampsia and Eclampsia. African Journal of Reproductive Health, 11, 89-94.

[12] Baczyk, D., Kingdom, J.C. and Uhlen, P. (2011) Calcium Signaling in Placenta. Cell Calcium, 49, 350-356.

[13] Seely, E.W., Wood, R.J., Brown, E.M. and Graves, S.W. (1992) Lower Serum Ionized Calcium and Abnormal Calciotropic Hormone Levels in Preeclampsia. The Journal of Clinical Endocrinology and Metabolism, 74, 1436-1440.

[14] Hache, S., Takser, L., LeBellego, F., Weiler, H., Leduc, L., Forest, J.C., et al. (2011) Alteration in Calcium Homeostasis in Primary Preeclamptic Syncytiotrophoblasts: Effect on Calcium Exchange in Placenta. Journal of Cellular and Molecular Medicine, 15, 654-657.

[15] Lai, J., Poon, L.C.Y., Bakalis, S., Chiriac, R. and Nicolaides, K.H. (2013) Systolic, Diastolic and Mean Arterial Pressure at 30 - 33 Weeks in the Prediction of Preeclampsia. Fetal Diagnosis and Therapy, 33, 173-181.

[16] Tayyar, A., Krithinakis, A., Wright, A., Wright, D. and Nicolaides, K.H. (2016) Mean Arterial Pressure at 12, 22, 32 and 36 Weeks' Gestation in Screening for Pre-Eclampsia. Ultrasound in Obstetrics \& Gynecology, 47, 573-579. https://doi.org/10.1002/uog.15815

[17] Park, H.J., Shim, S.S. and Cha, D.H. (2015) Combined Screening for Early Detection of Pre-Eclampsia. International Journal of Molecular Sciences, 16, 17952-17974. https://doi.org/10.3390/ijms160817952

[18] Katz, E.D. and Ruoff, B.E. (2004) Commonly Used Formulas and Calculations. In: Roberts. Clinical Procedures in Emergency Medicine, 4th Edition, Elsevier Mosby Publishing, Philadelphia.

[19] Rebelo, F., Farias, D.R., Mendes, R.H., Schlussel, M.M. and Kac, G. (2015) Blood Pressure Variation Throughout Pregnancy According to Early Gestational BMI: A Brazilian Cohort. Arquivos Brasileiros de Cardiologia, 104, 284-291. https://doi.org/10.5935/abc.20150007

[20] Soma-Pillay, P., Nelson-Piercy, C., Tolppanen, H. and Mebazaa, A. (2016) Physiological Changes in Pregnancy. Cardiovascular Journal of Africa, 27, 89-94.

https://doi.org/10.5830/CVJA-2016-021 
[21] Klein, H.H. and Pich, S. (2003) Cardiovascular Changes during Pregnancy. Herz, 28, 173-174. https://doi.org/10.1007/s00059-003-2455-2

[22] Sanghavi, M. and Rutherford, J.D. (2014) Cardiovascular Physiology of Pregnancy. Circulation, 130, 1003-1008. https://doi.org/10.1161/CIRCULATIONAHA.114.009029

[23] Khalil, A., Garcia-Mandujano, R., Maiz, N., Elkhouli, M. and Nicolaides, K.H. (2014) Longitudinal Changes in Uterine Artery Doppler and Blood Pressure and Risk of Pre-Eclampsia. Ultrasound in Obstetrics \& Gynecology, 43, 541-547. https://doi.org/10.1002/uog.13257

[24] Talaulikar, V.S. and Shehata, H. (2012) Uric Acid: Is It Time to Give Up Routine Testing in Management of Pre-Eclampsia? Obstetric Medicine, 5, 119-123. https://doi.org/10.1258/om.2011.110075

[25] Powers, R.W., Bodnar, L.M., Ness, R.B., Cooper, K.M., Gallaher, M.J., Frank, M.P., et al. (2006) Uric Acid Concentrations in Early Pregnancy among Preeclamptic Women with Gestational Hyperuricemia at Delivery. American Journal of Obstetrics and Gynecology, 194, 160.e1-160.e8. https://doi.org/10.1016/j.ajog.2005.06.066

[26] Wu, Y., Xiong, X., Fraser, W.D. and Luo, Z.C. (2012) Association of Uric Acid with Progression to Preeclampsia and Development of Adverse Conditions in Gestational Hypertensive Pregnancies. American Journal of Hypertension, 25, 711-717. https://doi.org/10.1038/ajh.2012.18

[27] Patel Tejal, D.A. (2014) Relationship of Serum Uric Acid Level to Maternal and Perinatal Outcome in Patients with Hypertensive Disorders of Pregnancy. Gujarat Medical Journal, 69, 45-47.

[28] Masse, J., Forest, J.C., Moutquin, J.M., Marcoux, S., Brideau, N.A. and Belanger, M. (1993) A Prospective Study of Several Potential Biologic Markers for Early Prediction of the Development of Preeclampsia. American Journal of Obstetrics and Gynecology, 169, 501-508. https://doi.org/10.1016/0002-9378(93)90608-L

[29] Calvert, S.M., Tuffnell, D.J. and Haley, J. (1996) Poor Predictive Value of Platelet Count, Mean Platelet Volume and Serum Urate in Hypertension in Pregnancy. European Journal of Obstetrics \& Gynecology and Reproductive Biology, 64, 179-184.

[30] Odendaal, H.J. and Pienaar, M.E. (1997) Are High Uric Acid Levels in Patients with Early Pre-Eclampsia an Indication for Delivery? South African Medical Journal, 87, 213-218.

[31] Zhou, G., Holzman, C., Luo, Z. and Margerison, C. (2018) Maternal Serum Uric Acid Levels and Blood Pressure during Pregnancy: A Community-Based Cohort Study. European Journal of Obstetrics \& Gynecology and Reproductive Biology, 222, 64-69. https://doi.org/10.1016/j.ejogrb.2018.01.008

[32] De Jong, C.L., Paarlberg, K.M., van Geijn, H.P., Schipper, E.J., Bast, A., Kostense, P.J. and Dekker, G.A. (1997) Decreased First Trimester Uric Acid Production in Future Preeclamptic Patients. Journal of Perinatal Medicine, 25, 347-352. https://doi.org/10.1515/jpme.1997.25.4.347

[33] Akahori, Y., Masuyama, H. and Hiramatsu, Y. (2012) The Correlation of Maternal Uric Acid Concentration with Small-for-Gestational-Age Fetuses in Normotensive Pregnant Women. Gynecologic and Obstetric Investigation, 73, 162-167. https://doi.org/10.1159/000332391

[34] Nair, A. and Savitha, C. (2017) Estimation of Serum Uric Acid as an Indicator of Severity of Preeclampsia and Perinatal Outcome. The Journal of Obstetrics and Gynecology of India, 67, 109-118. https://doi.org/10.1007/s13224-016-0933-8 
[35] Yalamati, P., Bhongir, A.V., Betha, K., Verma, R. and Dandge, S. (2015) Relationship of Serum Uric Acid, Serum Creatinine and Serum Cystatin C with Maternal and Fetal Outcomes in Rural Indian Pregnant Women. International Journal of Reproduction, Contraception, Obstetrics and Gynecology, 4, 1505-1510. https://doi.org/10.18203/2320-1770.ijrcog20150737

[36] Bainbridge, S.A., von Versen-Hoynck, F. and Roberts, J.M. (2009) Uric Acid Inhibits Placental System A Amino Acid Uptake. Placenta, 30, 195-200. https://doi.org/10.1016/j.placenta.2008.10.015

[37] Bainbridge, S.A., Roberts, J.M., von Versen-Hoynck, F., Koch, J., Edmunds, L. and Hubel, C.A. (2009) Uric Acid Attenuates Trophoblast Invasion and Integration into Endothelial Cell Monolayers. American Journal of Physiology-Cell Physiology, 297, C440-C450. https://doi.org/10.1152/ajpcell.00593.2008

[38] Feig, D.I., Nakagawa, T., Karumanchi, S.A., Oliver, W.J., Kang, D.H., Finch, J., et al. (2004) Hypothesis: Uric Acid, Nephron Number, and the Pathogenesis of Essential Hypertension. Kidney International, 66, 281-287. https://doi.org/10.1111/j.1523-1755.2004.00729.x

[39] Williams, K.P. and Galerneau, F. (2002) The Role of Serum Uric Acid as a Prognostic Indicator of the Severity of Maternal and Fetal Complications in Hypertensive Pregnancies. Journal of Obstetrics and Gynaecology Canada, 24, 628-632. https://doi.org/10.1016/S1701-2163(16)30193-1

[40] Hanna, B. (2009) The Role of Calcium Correction during Normal Pregnancy at Third Trimester in Mosul. Oman Medical Journal, 24, 188-194. https://doi.org/10.5001/omj.2009.37

[41] Tran, H.A. (2005) Biochemical Tests in Pregnancy. Australian Prescriber, 28, 136-139. https://doi.org/10.18773/austprescr.2005.076

[42] Bautista, L.E. (2016) Calcium and Linoleic Acid Supplements in the Prevention of Preeclampsia. Colombia Médica (Cali), 47, 68.

[43] Elmugabil, A., Hamdan, H.Z., Elsheikh, A.E., Rayis, D.A., Adam, I. and Gasim, G.I. (2016) Serum Calcium, Magnesium, Zinc and Copper Levels in Sudanese Women with Preeclampsia. PLoS ONE, 11, e0167495. https://doi.org/10.1371/journal.pone.0167495

[44] Von Dadelszen, P., Firoz, T., Donnay, F., Gordon, R., Justus Hofmeyr, G., Lalani, S., et al. (2012) Preeclampsia in Low and Middle Income Countries-Health Services Lessons Learned from the PRE-EMPT (PRE-Eclampsia-Eclampsia Monitoring, Prevention and Treatment) Project. Journal of Obstetrics and Gynaecology Canada, 34, 917-926. https://doi.org/10.1016/S1701-2163(16)35405-6

[45] Richards, D.G., Lindow, S.W., Carrara, H., Knight, R., Haswell, S.J. and Van der Spuy, Z.M. (2014) A Comparison of Maternal Calcium and Magnesium Levels in Pre-Eclamptic and Normotensive Pregnancies: An Observational Case-Control Study. BJOG, 121, 327-336. https://doi.org/10.1111/1471-0528.12436

[46] Vafaei, H., Dalili, M. and Hashemi, S.A. (2015) Serum Concentration of Calcium, Magnesium and Zinc in Normotensive versus Preeclampsia Pregnant Women: A Descriptive Study in Women of Kerman Province of Iran. Iranian Journal of Reproductive Medicine, 13, 23-26.

[47] Gupta, A., Kant, S., Pandav, C.S., Gupta, S.K., Rai, S.K. and Misra, P. (2016) Dietary Calcium Intake, Serum Calcium Level, and Their Association with Preeclampsia in Rural North India. Indian Journal of Community Medicine, 41, 223-227. https://doi.org/10.4103/0970-0218.183591

[48] Singh, R.B., Singh, N.K., Mehta, P.J. and Rastogi, S.S. (1987) Does Calcium Aggra- 
vate and Cause Hypertension? Acta Cardiologica, 42, 445-467.

[49] Shekhar, S., Gupta, N., Kirubakaran, R. and Pareek, P. (2016) Oral Nifedipine versus Intravenous Labetalol for Severe Hypertension during Pregnancy: A Systemic Review and Meta-Analysis. BJOG, 123, 40-47. https://doi.org/10.1111/1471-0528.13463

[50] Luizon, M.R., Palei, A.C., Cavalli, R.C. and Sandrim, V.C. (2017) Pharmacogenetics in the Treatment of Pre-Eclampsia: Current Findings, Challenges and Perspectives. Pharmacogenomics, 18, 571-583. https://doi.org/10.2217/pgs-2016-0198

[51] Addel-Aleem, H., Merialdi, M., Elsnosy, E.D., et al. (2009) The Effect of Calcium Supplementation during Pregnancy on Fetal and Infant Growth: A Nested Randomized Controlled Trial within WHO Calcium Supplementation Trial. The Journal of Maternal-Fetal \& Neonatal Medicine, 22, 94-100. https://doi.org/10.1080/14767050802464569

[52] Abalos, E., Merialdi, M., Wojdyla, D., Carroli, G., Campodonico, L., Yao, S.E., et al. (2010) Effects of Calcium Supplementation on Fetal Growth in Mothers with Deficient Calcium Intake: A Randomized Controlled Trial. Paediatric and Perinatal Epidemiology, 24, 53-62. https://doi.org/10.1111/j.1365-3016.2009.01088.x

[53] Sabour, H., Hossein-Nezhad, A., Maghbooli, Z., Madani, F., Mir, E. and Larrijani, B. (2006) Relationship between Pregnancy Outcomes and Maternal Vitamin D and Calcium Intake: A Cross-Sectional Study. Gynecological Endocrinology, 22, 585-589. https://doi.org/10.1080/09513590601005409

[54] Sarma, D., Saikia, U.K. and Das, D.V. (2018) Fetal Skeletal Size and Growth are Relevant Biometric Markers in Vitamin D Deficient Mothers: A North East India Prospective Cohort Study. Indian Journal of Endocrinology and Metabolism, 22, 212-216. https://doi.org/10.4103/ijem.IJEM_652_17

[55] Tayal, D., Goswami, B., Patra, S.K., Tripathi, R. and Khaneja, A. (2014) Association of Inflammatory Cytokines, Lipid Peroxidation End Products and Nitric Oxide with the Clinical Severity and Fetal Outcome in Preeclampsia in Indian Women. Indian Journal of Clinical Biochemistry, 29, 139-144. https://doi.org/10.1007/s12291-013-0320-5

[56] Aabidha, P.M., Cherian, A.G., Paul, E. and Helan, J. (2015) Maternal and Fetal Outcome in Pre-Eclampsia in a Secondary Care Hospital in South India. Journal of Family Medicine and Primary Care, 4, 257-260. https://doi.org/10.4103/2249-4863.154669

[57] Seyom, E., Abera, M., Tesfaye, M. and Fentahun, N. (2015) Maternal and Fetal Outcome of Pregnancy Related Hypertension in Mettu Karl Referral Hospital, Ethiopia. Journal of Ovarian Research, 8, 10. https://doi.org/10.1186/s13048-015-0135-5 